\title{
ERRÂNCIA E NOMADISMO FEMININO: O CASO DE DUAS MULHERES TRECHEIRAS
}

\author{
ERRANCIA $\Upsilon$ NOMADISMO FEMENINO: \\ EL CASO DE DOS MUJERES TRECHEIRAS \\ WANDERING AND FEMALE NOMADISM: \\ THE CASE OF TWO FEMALE WANDERERS
}

\section{Luciana Codognoto da Silva ${ }^{1}$ e José Sterza Justo ${ }^{2}$}

${ }^{1}$ Universidade Federal de Mato Grosso do Sul, Nova Andradina/MS, Brasil

${ }^{2}$ Universidade Estadual Paulista, Assis/SP, Brasil

\begin{abstract}
RESUMO: Para investigar o papel da mobilidade na constituição dos gêneros, realizamos uma pesquisa com mulheres trecheiras - mulheres sem residência fixa, transitando de cidade em cidade e que utilizam os serviços de assistência social. Participaram do estudo duas mulheres usuárias dos serviços da casa de acolhimento aos migrantes de uma cidade do Estado do Mato Grosso do Sul, situada na divisa dos Estados de São Paulo e Paraná. Mediante a perspectiva cartográfica e utilizando entrevistas abertas, observamos trajetórias marcantes de ruptura com a vida sedentária e a passagem para uma vida em trânsito, desprendida de vínculos com a família, o trabalho e os papéis tradicionais atribuídos à mulher. Elas buscaram na errância uma alternativa de vida melhor, uma tentativa de fuga dos problemas e das violências de gênero vividas no ambiente doméstico e no relacionamento familiar e foram aprendendo, dia a dia, no trecho, a viverem como trecheiras.
\end{abstract}

PALAVRAS-CHAVE: Mulheres; Nomadismo; Errância.

RESUMEN: Para investigar el papel de la movilidad en la constitución de los géneros, realizamos una encuesta a mujeres que trabajaban con mujeres trecheiras - mujeres sin residencia fija, transitando de una ciudad a otra, y que usan los servicios de asistencia social. Participaron del estudio dos mujeres usuarias de los servicios de refugio para migrantes de una ciudad en el estado de Mato Grosso do Sul, ubicado en la frontera de los estados de São Paulo y Paraná. A través de la perspectiva cartográfica y el uso de entrevistas abiertas, observamos trayectorias notables de ruptura con la vida sedentaria y el paso a una vida en tránsito, separada de los lazos con la familia, el trabajo y los roles tradicionales atribuidos a las mujeres. Buscaron en la errancia una mejor alternativa de vida, un intento de escapar de los problemas y la violencia de género experimentada en el entorno doméstico y las relaciones familiares, y aprendieron, día a día, a vivir como trecheiras.

PALABRAS CLAVE: Mujeres; Nomadismo; Errancia.

ABSTRACT: In order to investigate the role of mobility in the constitution of genders, we conducted a survey of women wanderers - women without fixed residence, moving from city to city and using social assistance services. The study included two women who use migrant shelter services from a city in the state of Mato Grosso do Sul, located on the border of the states of São Paulo and Paraná, Brazil. Through the cartographic perspective and using open interviews, we observed remarkable trajectories of rupture with sedentary life and the passage to a life in transit, detached from ties with family, work and the traditional roles attributed to women. They sought, in their wanderings, a better life alternative, an attempt to escape the problems and gender-based violence experienced in the domestic environment and family relationships, and they learned, day by day, to live as wanderers.

KEYWORDS: Women; Nomadism; Wandering. 


\section{Introdução}

A figura do nomadismo tem se expandido na atualidade, impregnando teorias, filosofias, práticas sociais, vivências emocionais, afetivas, relacionamentos diversos e tantos outros aspectos da vida humana. A valorização do movimento e das cineses é perfeitamente compreensível como construção histórica do processo civilizatório ocidental. A modernidade e o capitalismo, com suas pretensões universalizantes e expansionistas, assentadas em ideários, tais como o de liberdade, inovação, ordem e progresso, fizeram o mundo girar em velocidades cada vez maiores, potencializando a vida e, ao mesmo tempo, criando formas cada vez mais sofisticadas de gestão da mobilidade, segundo afirmou Virilio (1996).

Justo (2012), em suas pesquisas com andarilhos de estrada, argumenta que o tempo, o espaço e a velocidade são categorias de análise fundamentais no campo da Psicologia e da produção de subjetividade. Argumenta, ainda, que andarilhos de estrada e trecheiros podem ser considerados as expressões mais radicais da condição de itinerância, trânsito e mobilidade no mundo atual. Em sua publicação mais recente, Justo (2018) ressalta que a mobilidade foi fundamental para a constituição da humanidade e que junto ao homo faber, ao homo erectus e ao homo sapiens estiveram também o homo viator e o homo vaga como portadores de atributos indispensáveis para que o ser humano pudesse chegar ao que é hoje.

Situados numa perspectiva que relaciona gênero e mobilidade, perguntamos: se a mobilidade é tão essencial à humanidade, como a constituição e as relações de gênero são afetadas por ela? Se os homens que vivem em trânsito, caminhando pelas estradas ou migrando de cidade em cidade, são considerados expressões radicais de mobilidade na sociedade atual, o que dizer das mulheres, especificamente daquelas que percorrem trechos de uma cidade a outra?

A partir destes questionamentos, o objetivo deste estudo é discutir as questões de gênero relacionadas à mobilidade, mediante relatos de experiências de duas mulheres que vivem em condição de perambulação de cidade em cidade, passando a abrigar-se, temporariamente, em um município de médio porte populacional, localizado no interior do Estado de Mato Grosso do Sul - MS. Buscaremos examinar como as mulheres, denominadas pela literatura científica de trecheiras, vivem as diversas facetas da feminilidade, como os modos de vida antes e depois da deserção e as particularidades femininas no trecho, em um espaço radicalmente oposto àquele ambiente de confinamento e de subalternidade, tradicionalmente reservado à mulher na sociedade e na cultura.

A pesquisa foi realizada em uma cidade de médio porte populacional, localizada na região sudeste do Estado de Mato Grosso do Sul (MS). Trata-se de uma típica cidade interiorana, situada nos limites geográficos das divisas dos Estados de São Paulo e Paraná, contando com uma população de 54 mil habitantes (IBGE [Instituto Brasileiro de Geografia e Estatística], 2019). Observamos que o fenômeno da migração esteve muito presente desde a fundação do município, que, segundo dados levantados pelo IBGE (2019), ocupa a nona colocação no ranking do Produto Interno Bruto - PIB do estado e a posição de sétimo maior município de Mato Grosso do Sul, tornando-se importante rota de passagem para homens e mulheres popularmente denominados de migrantes.

São duas as instituições responsáveis pelo trabalho com essas populações no município: o Centro de Referência Especializado da Assistência Social - CREAS, que realiza a abordagem pelas ruas, e a Casa do Migrante, local onde realizamos nossa pesquisa de campo. A Casa do Migrante "CAMINA" é uma instituição que atende homens e mulheres 
em situação de passagem/transição pelo município. Foi fundada pela Igreja Católica do município em 03 de agosto de 1996. A instituição tem se mantido por meio de convênios com os governos estadual e municipal - recursos financeiros e concessão de funcionários para desempenhar atividades profissionais -, além de doações de pessoas físicas e jurídicas e da própria Igreja. Realiza uma média de 70 atendimentos durante o mês; desses, $10 \%$ são de mulheres, o que despertou bastante a nossa atenção.

Para fins de elaboração desta pesquisa, dividimos este estudo em quatro partes. $\mathrm{Na}$ primeira, discorreremos sobre os conceitos de errância e nomadismo. Na segunda, apresentaremos o método utilizado na pesquisa, dando ênfase à cartografia, construída passo a passo com as nossas participantes. Na terceira, exibiremos, em formato de narrativas, duas histórias de vida de mulheres que participaram do estudo e que se denominaram mulheres trecheiras. Por fim, apresentaremos as análises e discussões das histórias contadas pelas participantes a partir de uma perspectiva que relaciona o tema mobilidade, gênero e nomadismo feminino.

\section{Nomadismo e Errância Feminina}

O termo errância vem designar um caminhar ou deslocar-se sem rumo, sem qualquer previsibilidade de uma rota ou lugar de destino. O nomadismo, por sua vez, se refere a deslocamentos constantes de um lugar a outro, admitindo retornos, circularidades ou previsibilidades de rotas a serem percorridas. Neste estudo, a noção de errância se aplica melhor ao caso dos andarilhos, e o nomadismo, ao caso dos trecheiros, podendo, também, ser utilizado para caracterizar as movimentações ou as flâneries citadinas das pessoas em situação de rua.

Entendemos o termo trecheiras a partir de Justo (2012) e Freitas (2014), que o diferencia de outras terminologias, como migrantes, andarilhos e mendigos. Para Justo (2012), andarilhos seriam as pessoas que vivem andando a pé pelos acostamentos de rodovias, enquanto que trecheiros seriam as pessoas que vivem em constante trânsito, de cidade em cidade, caminhando a pé, como os andarilhos, ou utilizando passagens de ônibus concedidas por serviços de assistência social dos municípios. Ao fazer referência ao seu sentido etimológico, Justo (2012, p. 117), afirma que o termo trecho representa: "espaço de tempo ou de lugar, intervalo, parte de um todo, segmento".

De maneira semelhante, Freitas (2014, p. 16) afirma que o termo trecheiros faz referência aos "sujeitos que perambulam de cidade em cidade, permanecendo nas ruas e sobrevivendo de ajuda de serviços públicos de assistência social ou de achaques (pedido de ajuda feito com educação, esperteza e justificativa convincentes)". Ademais, Justo (2012) afirma que o termo trecho faz referência a uma parte do caminho não determinado, que vai sendo construído pelo sujeito no decorrer de sua caminhada, em parceria com entidades e instituições que o auxiliam nesta travessia.

Para ambos os autores, Justo (2012) e Freitas (2014), o que diferencia andarilhos e trecheiros seria justamente o grau de deambulação, ou seja, enquanto os andarilhos procuram viver exclusivamente transitando pelas rodovias, buscando abrigos improvisados debaixo de pontes e viadutos, em casas abandonadas às margens das rodovias ou em coberturas de pontos de ônibus e recantos de postos de serviços, os trecheiros preferem se acomodar, temporariamente, nas cidades, fazendo delas o suporte para prosseguimento de 
sua viagem, com a ajuda de entidades de assistência social ou da população local. Em suma, para os referidos autores, os andarilhos vivem nas estradas, enquanto que os trecheiros fazem do trânsito de cidade em cidade sua estratégia de sobrevivência.

Em Nascimento (2012) e Justo (2012) é possível observar que, mesmo em uma época que se privilegiam movimentações, desapegos, efemeridade, fluidez, transitoriedade e outras experiências de ampliação dos espaços e de aceleração da vida, andarilhos e trecheiros, que poderiam ser tomados como expressões radicais desse mundo vertiginoso, acabam sendo percebidos como seres malvistos e rejeitados. A errância de trecheiros e andarilhos, juntamente com o modo de vida das pessoas em situação de rua, são objeto de estigmas que os retratam pejorativamente como sinônimos de "vagabundagem", "doença mental" e “desestruturação familiar”, tal como enfatizou Nascimento (2012).

Pesquisas e discussões sobre gênero e nomadismo vêm acompanhando o florescimento e a expansão de estudos sobre identidade, sexualidade e feminilidade. Soihet e Pedro (2007), percorrendo a história desse campo de estudos, mencionam a relação entre gênero e nomadismo, mediante críticas à construção do feminino pela via da produção de representações fixas e da disseminação de identidades cristalizadas, que associam a mulher a atributos naturalizados e imutáveis, tais como maternidade, afazeres domésticos e amor romântico.

No âmbito internacional há alguns estudos, como de Helleiner (1997), que examina a articulação entre racismo e gênero na Irlanda, por meio dos discursos construídos sobre a ideologia da domesticidade feminina, os quais, segundo a autora, obscureceram a existência de mulheres viajantes. A autora chama a atenção para o redirecionamento dos processos econômicos e políticos e as relações de poder que produzem diferenças e desigualdades de gênero, etnia e racismo no contexto irlandês da década de 1960.

Casey (2014) examina as crenças e as práticas culturais e morais que contribuíram para a constituição de gênero e o rompimento com o status quo de mulheres ciganas viajantes do norte da Inglaterra. Salienta a autora que as mulheres ciganas enfrentam maiores desafios no processo migratório que os homens, por conta de questões de gênero, uma vez que o homem é visto social e culturalmente como um ser ativo economicamente, enquanto que as mulheres foram, durante muito tempo, relegadas ao plano doméstico e ao sedentarismo. Para ela, as mulheres ciganas viajantes expressariam importante estratégia de resistência ou de não conformidade aos modelos hegemônicos de feminilidade e masculinidade na Europa.

Por fim, para Swain (2000), o conceito de nomadismo utilizado nas discussões de gênero e das subjetivações da feminilidade não visa propriamente a negar as estruturas identitárias, mas sim a criar ferramentas para desestabilizá-las e abrir o campo da experiência das mulheres, propiciando suas migrações por diferentes espaços e lugares psicossociais. Não se trata apenas de investigar as espacialidades criadas em torno dos gêneros masculino e feminino e as geopolíticas exercidas por meio das relações de gênero, mas também de focalizar as diferenças de mobilidade, transitividade e percursos que se distribuem distintamente entre homens e mulheres. 


\section{Método}

\section{1- Cartografia: implicações teóricas e práticas}

Em nosso estudo, recorremos à abordagem qualitativa de pesquisa em Psicologia, tendo como método a cartografia. Inspirada nas ideias de Gilles Deleuze \& Felix Guatarri (1995), a cartografia representa um rizoma - um sistema conceitual aberto, que não tem começo e nem fim, que está sempre no meio, no intermezzo - algo que nos remete à ideia de mulheres e errância. Os referidos autores buscaram na biologia, mais especificamente na botânica, a definição do conceito de rizoma - raiz com um crescimento diferenciado e sem uma orientação definida - para aplicá-lo ao campo da filosofia, salientando ser o rizoma um modelo de resistência aos padrões éticos, estéticos e políticos, constituído por linhas abertas e não por processos fechados, lineares e acabados.

Por este grande fluxo - a cartografia -, procuramos mapear as expressões das feminilidades nômades ou errantes na cultura e nas experiências de vida singulares, concretamente constituídas de mulheres que vivem nos trechos. Logo, a transitoriedade foi uma situação bastante comum neste campo de pesquisa, tal como apontam os estudos de Justo (2012), o que exigiu de nós certa mobilidade e disponibilidade para deslocamentos, trânsitos e nomadismos tanto no campo teórico - bibliografia insuficiente sobre o tema, sobretudo no que se refere à Psicologia e aos estudos de mulheres trecheiras - quanto no campo empírico da pesquisa - mediante o traquejo para lidar com as resistências e as dificuldades iniciais de contato e fala das participantes.

Nesta pesquisa, buscamos estabelecer uma condição de flexibilidade no enquadre da relação entrevistadora/entrevistadas e na singularidade da situação de cada entrevista. Os horários e os dias das entrevistas, bem como as condições para sua realização se deram a partir do contato com cada mulher entrevistada, mediada pela assistente social da Instituição, que atuou como intermediária neste processo, nos informando sobre a entrada de mulheres na Casa e nos apresentando a elas. A partir deste primeiro contato, as entrevistas aconteceram individualmente em uma sala reservada com cada participante.

Para Rolnik (1997), a prática do/a cartógrafo/a é eminentemente política, uma vez que ela não visa a seguir um protocolo normalizado, mas sim participar ativamente da constituição dos territórios existenciais - modos de vida das pessoas - e da realidade psicossocial delas. Por isso, a cartografia se ajustou muito bem a esta pesquisa, uma vez que a imprevisibilidade, o inesperado e o casual se fizeram muito presentes em nosso campo de investigação, não nos permitindo estabelecer roteiros preestabelecidos, passos programados e horários previamente agendados com as nossas participantes. Ao contrário, construímos o nosso percurso cartográfico a partir da ideia de rizoma de Deleuze e Guatarri (1995), um método edificado a cada etapa, a cada passo, em um processo nômade com as nossas participantes, visando a desconstruir o significado rígido da pesquisa acadêmica Psicologia, tal como veremos a seguir.

\section{2- As Entrevistas e Suas Formas de Tratamento}

As entrevistas foram gravadas, transcritas e, posteriormente, autorizadas pelas participantes, mediante a assinatura do TCLE - Termo de Consentimento Livre Esclarecido -, aprovado pelo Comitê de Ética e Pesquisa (CEP) de uma universidade pública. Elas foram 
realizadas nas dependências da Casa do Migrante do Município, em uma sala reservada, tendo a duração de aproximadamente uma hora. O diálogo com as participantes transcorreu com um mínimo de perguntas. A postura básica da entrevistadora foi a de ouvir e deixar as entrevistadas se expressarem livremente. As intervenções foram no sentido de pedir esclarecimentos, quando necessário, ou formular perguntas relacionadas ao que denominamos de eixos disparadores, formado por temas, como: perfil das participantes, momento de ruptura, acontecimentos e conflitos que deflagraram a deserção, vida no trecho e perspectivas de futuro, tal como apontam os estudos de Justo (2012, 2018), Nascimento (2012) e Freitas (2014).

Na Casa do Migrante, local de nossa pesquisa, além de homens, mulheres com idades entre 18 e 59 anos buscam abrigo temporário na Instituição mediante demanda própria. Em sua maioria, as mulheres são consideradas, pelos funcionários da Casa, as pessoas mais difíceis no âmbito dos relacionamentos interpessoais, por serem mais fechadas e de pouco diálogo e contato afetivo e interpessoal, se comparadas aos homens que também passam pela Instituição. Trata-se de mulheres sem um local de destino fixo e de vínculos afetivos e/ou familiares pouco mencionados por elas. Além de representarem um número reduzido, as mulheres também apresentam maiores dificuldades de se relacionar e de interagir com outras pessoas da cidade e com os próprios funcionários da Casa, fator que, igualmente, chamou a nossa atenção.

Para fins de análise e discussão da temática "gênero, mulheres, errâncias e nomadismos", escolhemos apresentar, em formato de narrativas, duas das histórias de vida de mulheres trecheiras entrevistadas ao longo da pesquisa. Destacamos que os nomes citados durante a pesquisa foram escolhidos pelas próprias participantes, a partir de uma lista apresentada a elas, constando apenas títulos e significados de pedras preciosas. Buscamos, com isso, dar visibilidade aos preciosos discursos e à riqueza de histórias contadas por elas. Ademais, optamos, por questões éticas, não fazer referência direta ao nome do município onde ocorreu este estudo, trazendo apenas características que o identifique em termos geopolíticos e como importante campo psicossocial da pesquisa.

A leitura e a interpretação das narrativas serão realizadas a partir da análise do discurso, proposta por Michel Foucault. Em A Ordem do Discurso (2007), Foucault destaca três importantes procedimentos que permitem controlar e validar os discursos - a exclusão - da palavra proibida e da segregação da loucura -, a interdição - que consiste no controle do que pode ser dito, em que circunstância e a quem é permitido falar. O último procedimento se refere, segundo o autor, à:

Rarefação, desta vez, dos sujeitos que falam; ninguém entrará na ordem do discurso se não satisfazer a certas exigências ou se não for, de início, qualificado para fazê-lo. Mais precisamente: nem todas as regiões do discurso são igualmente abertas e penetráveis; algumas são altamente proibidas... enquanto outras parecem quase abertas a todos os ventos e postas, sem restrição prévia, à disposição de cada sujeito que fala. (Foucault, 2007, p. 37)

A partir da ótica foucaultiana, podemos afirmar que, durante muito tempo, as mulheres, especialmente aquelas em situação de errância e nomadismo, estiveram pouco presentes na ordem do discurso - acadêmico e social -, não podendo, por vezes, narrar suas histórias e falar sobre as suas experiências errantes e de nomadismo em nome próprio. 


\section{Resultados e Discussões}

\section{A História de Safira}

"Eu perdi o meu medo, meu medo, meu medo da chuva.

Pois a chuva voltando 'pra' terra traz coisas do ar.

Aprendi o segredo, o segredo, o segredo da vida.

Vendo as pedras que choram sozinhas

no mesmo lugar".

- Raul Seixas ${ }^{1}$

Safira, uma mulher trecheira de 48 anos de idade, foi a primeira entrevistada. Contou que a sua infância foi vivida em uma pequena cidade do interior do Estado de São Paulo, onde sua família reside até hoje. Ela é a filha mais nova de oito irmãos, sendo três homens e cinco mulheres. Durante a sua gestação, a mãe alimentava o desejo de que a criança que esperava fosse um filho homem, e não uma mulher, para formar quatro casais de filhos.

Narrou, um tanto emocionada e nervosa, que a sua infância foi muito triste, pelo fato de sua família, principalmente de sua mãe, não aceitar a sua condição de mulher homossexual. Dizia ter sido vítima de violência, sendo alvo de agressões físicas e de ofensas morais por parte de sua família. Sempre falava de sua mãe com tom de revolta e, do pai, apenas mencionou que foi ele quem lhe apresentou a bebida alcoólica.

Aos 16 anos saiu de casa, indo morar com sua primeira companheira, com quem viveu durante quinze anos, constituindo a sua primeira experiência sexual e o seu primeiro amor. Relatou que se relacionou apenas com mulheres. Estudou até a oitava série do primeiro grau, trabalhando nos setores de reciclagem e de corte de cana-de-açúcar, bem como vendendo balas nas ruas. Começou a usar drogas aos 16 anos, a partir das experiências vividas com um de seus irmãos e com sua primeira parceira. Primeiramente, usou cocaína. Hoje, faz uso de cigarro, crack e bebidas alcoólicas.

Esteve presa seis vezes por motivos de violência, sendo levada a júri uma vez, por homicídio. Há vinte anos está migrando de cidade em cidade, preferindo ficar em vários lugares para não ter de voltar a ver a família. Denominou-se mulher trans e trecheira, dizendo que "Bui" era o seu nome de guerra. Questionada sobre seus planos para o futuro, alegou querer arrumar um emprego. Dizia que a rua "é uma guerra" e que nas ruas, "a pessoa tem de ser humilde e boa de conversa para sobreviver”. Dizia, ainda, que o seu maior medo foi a família, e, hoje, alegava não ter nenhum, uma vez que a rua a fortaleceu.

Com relação a sua passagem pela cidade, disse que "o povo aqui era bom, humilde e ajudava bastante ela”, dando comida, dinheiro, atenção e abrigo na Casa do Migrante do município. Durante a entrevista, sempre se dirigia à pesquisadora pelo nome de "abençoada”. No início da entrevista, se mostrou desconfiada, arredia, agitada, nervosa e chorando bastante, sobretudo ao falar de sua família e de sua infância. No final, mostrou-se receptiva e afetiva, verbalizando à pesquisadora que "ela era uma pessoa boa, porque a escutou e não a maltratou". 


\title{
A História de Esmeralda
}

\author{
"Tenho medo de viver em um lugar fechado \\ E só meu!"
}

Esmeralda, 40 anos, mulher parda e trecheira. Contou que sua família era de uma pequena cidade do interior do Estado de São Paulo. Começou a vida no trecho há quinze anos, depois de passar por duas perdas familiares muito significativas. A primeira delas foi a morte de seu único filho, há quinze anos, quando ele tinha cinco anos de idade, vítima de atropelamento, quando brincava na calçada de sua casa. A segunda foi a traição do marido, logo após a perda trágica do filho.

Dizia ter uma vida tranquila e boa antes desses dois acontecimentos. Era casada e vivia para a família, trabalhando em seu próprio lar, como dona de casa. Depois da morte do filho, a família a culpava pelo acontecido, alegando que ela não havia cuidado adequadamente dele enquanto brincava. Disse que: “após a morte do meu filho, tudo virou bagunça!". Separada do marido após a traição, foi à procura de trabalhos como doméstica, não tendo êxito, segundo ela, devido ao preconceito das pessoas por sua deficiência física - miopia e estrabismo fisicamente muito evidente, tendo necessidade de usar óculos com um alto grau.

Quando questionada sobre a possibilidade de ter tido outros filhos, ressaltou que passou por uma gravidez muito complicada e de risco, não podendo, segundo os médicos, ter outra gestação. Sobre a sua família, preferiu não dizer nada sobre seus irmãos e o ex-marido, chamando os primeiros de "parentes". Seus pais ainda estão vivos, mas, segundo ela, raramente tem contato com eles.

Faz uso de medicação controlada e de bebida alcoólica. É comum passar pela Casa do Migrante do município duas vezes por ano. Quando questionada sobre seus planos para o futuro, disse que, a partir de certa idade, pretende parar de migrar de cidade em cidade. Hoje, seu medo é "viver em lugar fechado e só dela", remetendo às lembranças da perda do filho e da traição do marido. Disse que gostava de namorar e não ter vínculos com ninguém.

Por fim, o que chamou bastante a atenção foi o seu cuidado com a higiene e sua aparência física, mantendo a sua bolsa e suas poucas peças de roupas sempre bem organizadas e muito limpas.

\section{Vidas de Mulheres no Trecho: duas histórias, alguns apontamentos}

O trecho da música destacada como epígrafe no primeiro relato não foi algo proposital, nem tampouco acidental ou ilustrativo. Trata-se, justamente, do trecho cantado pela participante no momento da entrevista, quando questionada sobre qual seria a música que mais retratava a sua vida antes e depois da deserção. Na canção, Medo da Chuva, Raul Seixas (1974) compara metaforicamente o perder o medo da chuva a não mais ter medo do novo, alegando não querer viver tal como "as pedras chorando sozinhas no mesmo lugar".

Considerado um dos pioneiros do rock no Brasil, durante os anos de 1970, Raul Seixas se apresentou como contestador e crítico, um poeta em busca de uma sociedade que ele denominou de alternativa. Em sua canção Medo da Chuva (1974), assim como em tantas outras que compõe o seu vasto repertório musical, o poeta retrata os relacionamentos circulantes e mutantes, não aprisionados a um espaço fechado, tampouco preso 
a um tempo paralisante, destinado a eternizar o movimento, as ideias e as relações. Quando o poeta se utiliza da metáfora "Eu perdi o meu medo da chuva", ele se refere à busca por uma vida nova, uma proposição crítica e bem à frente de seu tempo, tendo, por isso, sido considerado um louco ou, como ele mesmo cantando diz, "um maluco beleza".

Para Justo (2012), são muitas as condições que levam as pessoas em situação de nomadismo a desancorar de uma vida fixa e territorializada. A busca por um trabalho, a procura por serviços de assistência social para completar a viagem e a condição financeira estão entre as principais, também refletidas na vida de Esmeralda, ao assinalar a dificuldade encontrada para conseguir um trabalho remunerado antes de sua entrada na errância. Mas, também, não podemos nos esquecer de três importantes aspectos: a busca por uma situação melhor de vida, a fuga dos problemas gerados por uma vida indesejada e, principalmente as relações familiares, interpessoais e afetivas permeadas pela formação de vínculos negativos antes da deserção, fortemente evidenciadas tanto em Safira quanto em Esmeralda.

A precarização e a divisão sexual e social do trabalho, a segregação, o desemprego e a pobreza contribuem, por vezes, para que muitas pessoas optem radicalmente pelos caminhos da errância ou por outras formas de deslocamento, como no caso dos trabalhadores itinerantes e migrantes, que vão buscar em outras regiões do país ou em outros países, possibilidades de uma vida melhor. No caso específico da mulher, a itinerância ou a emigração em busca de trabalho ou de melhoria das condições econômicas coloca desafios e problemas específicos de gênero, podendo trazer um sentido de empoderamento e produzir mudanças significativas na experiência de ser mulher e em crenças e valores cristalizados a partir do contato delas com outras culturas, tal como enfatizam os estudos de Helleiner (1997) e Casey (2014).

Além do desemprego ou da busca de um trabalho melhor remunerado que impulsione as mulheres a se deslocarem para outros lugares como itinerantes, migrantes, ambulantes ou, até mesmo, como trecheiras - e, com isso, experimentarem mudanças significativas em suas identidades de gênero -, existem casos em que essas mudanças se configuram como visadas primárias e disparadoras do movimento de deserção e de clausuras impostas por estereotipias de gênero. Nesses casos, é possível pensarmos a errância enquanto um ato de coragem de muitas mulheres, ao abandonarem os referenciais hegemônicos de identidade feminina - como o casamento, a vida doméstica, a procriação e a docilidade - para viverem cotidianos transitórios, inesperados e improvisados, que rompem, drasticamente, com o modelo de mulher idealizado, romantizado e normatizado pela sociedade.

Exemplo disso é a história vivida por Safira, de 48 anos, mulher trecheira e lésbica. Alvo de uma série de violências morais, físicas e de gênero, sofridas no seio familiar antes da deserção, decide romper drasticamente com a família e seguir por rumos desconhecidos nos trechos. A violência sofrida na infância se perpetuou na idade adulta, agora, assumindo um papel de agressora, com seis passagens pela polícia, em virtude de cinco agressões físicas e um homicídio.

Embora nossas participantes rompam com os estereótipos e as mordaças sociais que se incrustam na feminilidade e subjugam a mulher, irrompendo barreiras espaciais geográficas e psicossociais, Safira e Esmeralda não se lançam tão arrebatadoramente à errância sem eira nem beira. Ambas cultivam desejos de sair, assim que possível, da vida nômade para uma vida assentada em territórios mais estáveis: Safira, almejando um emprego; Esmeralda, por sua vez, sonha em parar de circular de cidade em cidade, devido ao cansaço, mas, ainda, com medo de encarar as duas marcas familiares que colaboraram para 
a sua entrada na errância: a perda do filho pequeno e a traição do marido, se achando em desamparo afetivo, familiar, social e econômico diante daquele momento de dor, constituindo, de certa forma, uma violência de gênero.

De acordo com Sinués e Jiménez (2015), a violência de gênero se pauta em diferentes formas de violências, decorrentes do gênero ao qual as pessoas pertencem. Tal violência faz imperar a lógica da dominação, das desigualdades e das normatividades, tomando a chamada natureza dos corpos e sexos como definidora de privilégio e/ou exclusão das pessoas em uma sociedade patriarcal.

É preciso destacar que estas mulheres vivem, ainda hoje, sob fortes influências do patriarcado e de suas práticas de domesticação: Safira, pela condição de mulher lésbica; Esmeralda, por não ter desempenhado o papel esperado de mãe cuidadosa, culminando em uma série de ataques vindos de seus familiares, que a culpavam pela morte do filho. Sem o filho e, depois, sem o marido, Esmeralda sentiu-se vulnerável e desamparada, buscando, no trecho, uma nova oportunidade de vida.

Se Safira e Esmeralda escaparam de muitos espaços de aprisionamento da mulher, não conseguiram, porém, resistir ao processo de culpabilização que tanto amordaça a subjetividade feminina, segundo bem afirmaram Silva \& Sampaio (2016). Um exemplo disso é o trecho de fala de Esmeralda, quando, enfaticamente, nos diz que não conseguiria viver em um lugar fechado e só dela. O migrar de cidade em cidade implica fugir dos problemas e uma forma de não entrar em contato com seus sentimentos mais intensos, especialmente quando relatou não querer se relacionar por muito tempo e de forma fixa com ninguém, deixando transparecer o que Virilio (1996) acentua, ao dizer que o cerne da pós-modernidade seria, justamente, a efemeridade, o provisório, o descontínuo e o fragmentário no espaço, no tempo e nas relações.

Os hábitos evidenciados por nossas participantes demonstram que, mesmo na especificidade da vida trecheira - o que poderia ser visto como uma condição de vida reduzida à sobrevivência material e que restringe as possibilidades de diferenciação -, observarmos, no caso de Esmeralda, distinções entre o masculino e o feminino. Seu apreço por um cuidado pessoal, visível em sua aparência (roupas limpas e conservadas), demonstra um traço pessoal que é possível atribuir à condição de mulher ou ao feminino em nossa cultura. Por mais de uma vez, disse que gostava de andar limpinha, tomar banho, escovar os dentes, cortar e limpar as unhas, pentear o cabelo, dentre outros cuidados. Já Safira, além de se preocupar com a higiene, aparentava um visual considerado tipicamente masculino, ao fazer uso de bermudas abaixo do joelho, camisetas e um corte de cabelo muito curto.

É preciso também assinalar que o fato de se viver de forma itinerante ou em constante deslocamento, de um lugar a outro, no plano geográfico, não assegura, por si mesmo, mudanças identitárias relacionadas ao gênero, conforme assinala Casey (2014) em sua pesquisa com mulheres ciganas. Estes fatores evidenciam o que Butler retratou em sua obra Problemas de gênero, quando afirma que: "aquilo que define uma mulher certamente não é tudo o que ela é” (Butler, 2013, p. 54). Da mesma forma as mulheres ligadas ao contexto da errância, em especial àquelas a quem denominamos de trecheiras, não podem ser reduzidas a uma generalização ou, até mesmo, demarcarem características próprias de uma feminilidade hegemônica para que sejam consideradas mulheres.

Ainda sobre as questões de gênero, Safira nos apresenta o seu nome de guerra - Bui-, tal como era conhecida pelos companheiros e pelas companheiras no trecho. No Dicionário da Língua Portuguesa, Bui significa duas condições bastante contraditórias: de um lado, 
polir e lustrar; de outro, desgastar e perder. Termos, sem duvida, que evidenciam, e muito, a trajetória de Safira antes e depois da deserção. Mulher contraditória à sexualidade feminina hegemônica e às práticas sociais e sexuais conferidas ao feminino; àquela que brilha, "àquela que perdeu o medo da chuva", ao dizer que a rua a fortaleceu, um lugar de guerra que a tornou mais forte. Poderíamos afirmar que, para "polir" e "lustrar" sua sexualidade, assim como acontece em todo processo de polimento e lustro de pedras preciosas, Safira teve de desbastar sua vida, remover resíduos, desgastar e perder ou se desfazer daquilo que eclipsava sua sexualidade e todo um modo de existir associado a ela.

No caso de Safira, a linguagem, tal como enfatizam Freitas, Justo, e Peres (2017), não apresenta apenas uma função representativa ou expressiva, mas uma força de produção dos referentes ou das coisas às quais se refere. A palavra trecheira designa um modo de vida, ao mesmo tempo em que serve de referência identitária para as nossas participantes, participando dos engendramentos desse modo de viver para e entre elas. O mundo da estrada e do trecho é, essencialmente, para não dizermos que, quase exclusivamente, masculino. Porém, algumas mulheres apontam que os territórios, antes ocupados apenas por homens, passam a se constituir como possibilidade de vida e de novos começos para muitas delas, ainda que difíceis, tal como evidenciamos em Safira e Esmeralda.

\section{Considerações finais}

Ao longo desta pesquisa, observamos que as mulheres enfrentam, na errância, o desafio de terem de construir estratégias para assegurar a vida e a sobrevivência. Dito de outra forma, não existe qualquer legado cultural que possa ser transmitido de geração a geração, tampouco ensinamentos sobre essa forma de viver que dê a elas orientações básicas de vida, diferentemente do que ocorre com outras formas de vida socialmente instituídas. A cultura de trecheiras, como gírias, práticas cotidianas, valores, simbologias, relacionamentos, é completamente segregada e cultivada por e entre elas. A única maneira de se apropriar dessa cultura ou dessa forma de viver é ingressando nela ou se aproximando dela pelo contato direto com seus atores e suas atrizes.

São muitos os desafios e as dificuldades, sobretudo das mulheres, para se iniciarem no trecho, uma vez que se trata de um universo desconhecido e bem diferente da vida pregressa e sedentária vivida por elas antes da deserção. Não nasceram no trecho e nem passaram a infância nele. Portanto, quando decidiram "cair no mundo", ou seja, abandonar a vida sedentária e viver como trecheiras, perambulando de cidade em cidade, se defrontaram com um universo e um cotidiano muito diferentes dos quais estavam habituadas.

Se o desconhecimento e o silenciamento da vida de trecheiros tornam a inserção e a sobrevivência nas perambulações difíceis para os homens, segundo enfatizam Justo (2012) e Nascimento (2012), tanto mais para as mulheres, que não dispõem, muitas vezes, de experiências prévias de habitação desses espaços abertos e que poderiam servir de suporte para elas. Os homens, historicamente, foram incentivados a habitar a rua e o espaço público, a caminhar pela cidade, a transitar por relacionamentos e espaços sociais, enquanto que as mulheres estiveram relegadas ao sedentarismo e ao confinamento em determinados espaços geográficos e psicossociais, como a casa, o lar e a família.

Acreditamos que o fenômeno da migração, presente desde a fundação do município, contribuiu para que as participantes da pesquisa tivessem acesso mais facilmente a esse 
território geográfico e psicossocial. Por estar localizado nos limites físicos dos estados de São Paulo e Paraná e por se concentrar em um lugar privilegiado para o desenvolvimento econômico da região, é comum a passagem de pessoas pela Casa do Migrante com pedidos de ajuda, abrigo e condições para prosseguirem viagem, tal como aconteceu com Safira e, sobretudo com Esmeralda, que, pelo menos duas vezes ao ano, retorna à cidade pedindo algum tipo de auxílio.

Por fim, reiteramos que os propósitos desta pesquisa foram alcançados, uma vez que procuramos contribuir para a expansão dos estudos de gênero e errância feminina, focalizando um aspecto relevante dessa questão praticamente pouco explorado pela academia, em especial pela Psicologia - os modos de vida de mulheres que rompem com o papel identitário e hegemônico de feminilidade e de vida sedentária para adentrarem ao universo da errância, passando a viverem, assim, como mulheres trecheiras.

\section{Nota}

1 Seixas, R. (1974). Medo da chuva. In Gita, São Paulo: Philips Record.

\section{Referências}

Butler, J. (2013). Problemas de gênero: Feminismo e subversão da identidade. Rio de Janeiro: Civilização Brasileira.

Casey, R. (2014). 'Caravan wives' and 'decent girls': Gypsy-Traveller women's perceptions of gender, culture and morality in the North of England. Culture, Health E' Sexuality, 16(7), 806-819. Deleuze, G. \& Guattari, F. (1995). Mil platôs: Capitalismo e esquizofrenia. Rio de Janeiro: Editora 34. Foucault, M. (2007). A ordem do discurso. São Paulo: Edições Loyola.

Freitas, C. J. (2014). "Os indesejáveis": Agentes públicos e a gestão da mobilidade de trecheiros e pessoas em situação de rua. Dissertação de Mestrado, Programa de Pós-graduação em Psicologia, Universidade Estadual Paulista, Faculdade de Filosofia, Ciências e Letras de Assis, Assis, São Paulo.

Freitas, C. J., Justo, J. S., \& Peres, W. S. (2017). Nômades, errantes e queering: Ou da estranheza de se tornar estranho. Revista Artemis, 3(1), 108-119.

Helleiner, J. (1997). Women of the itinerant class: gender and anti-Traveller racism in Ireland. Women's Studies International Forum, 20(2), 275-287.

Justo, J. S. (2012). Vidas errantes: Políticas de mobilidade e experiência do tempo-espaço. Londrina/PR: Eduel.

IBGE. 2019. Estimativas da população residente no Município de Mato Grosso do Sul, com data de referência $1^{\circ}$ de janeiro de 2019. Brasília, DF. Recuperado de https://cidades.ibge.gov. $\mathrm{br} / \mathrm{brasil} / \mathrm{ms} /$ nova-andradina/pesquisa/33/29171? tipo=ranking 
Justo, J. S. (2018). Problemas e desafios das mobilidades psicossociais contemporâneas. In M. Nalli \& S. R. V. Mansano (Orgs.), Diagnósticos do presente (pp. 127-147). Maringá/PR: EDUEM.

Nascimento, E. C. (2012). Errância e nomadismo: Um estudo sobre a percepção de dirigentes e profissionais de instituições assistenciais em relação aos andarilhos de estrada. Tese de Doutorado, Programa de Pós-graduação em Psicologia, Universidade Estadual Paulista, Faculdade de Filosofia, Ciências e Letras de Assis, Assis, São Paulo.

Rolnik, S. (1997). Cartografia sentimental: Transformações contemporâneas do desejo. São Paulo: Estação Liberdade.

Silva, N. S \& Sampaio, L (2016). A culpa é da mulher: O anticristo, de Lars von Trier. Revista Observatório, 2(3), 43-61.

Sinués, O. A. \& Jiménez, R. M. (2015). Los géneros de la violencia: Una reflexión queer sobre la violencia de género. Barcelona/Madri: Egales Editorial.

Soihet, R. \& Pedro, J. M. (2007). A emergência da pesquisa da história das mulheres e das relações de gênero. Revista Brasileira de História, 27(54), 281-300.

Swain, T. N. (2000). A invenção do corpo feminino ou "a hora e a vez do nomadismo identitário?”. Textos de História, 8(12), 47-84.

Virilio, P. (1996). Velocidade e política. São Paulo: Estação Liberdade.

\section{LUCIANA CODOGNOTO DA SILVA}

https://orcid.org/0000-0002-6807-7800

Doutora em Psicologia e pós-doutora em Psicologia no Programa de Pósgraduação em Psicologia da Universidade Estadual Paulista Júlio de Mesquita Filho - UNESP/Assis. Professora Adjunta da Universidade Federal de Mato Grosso do Sul, campus de Nova Andradina - UFMS/CPNA.

Endereço: UFMS/CPNA, Rodovia MS 134, Km 3, Jardim Universitário, CEP 79750000, Nova Andradina/MS.

E-mail: 1upsico.codognoto@gmail.com

\section{JOSÉ STERZA JUSTO}

\section{https://orcid.org/0000-0002-5472-9900}

Doutor em Psicologia (Psicologia Social) pela Pontifícia Universidade Católica de São Paulo e Livre-Docência em Psicologia do Desenvolvimento pela UNESP-Campus de Assis. Professor Livre-Docente do Programa de Pósgraduação em Psicologia da Faculdade de Ciências e Letras da Universidade Estadual Paulista (UNESP-Campus de Assis).

E-mail: sterzajusto@yahoo.com.br 


\begin{tabular}{|c|c|}
\hline Histórico & $\begin{array}{l}\text { Submissão: 11/01/2019 } \\
\text { Revisão: 01/11/2019 } \\
\text { Aceite: 24/01/2020 }\end{array}$ \\
\hline $\begin{array}{l}\text { Contribuição } \\
\text { dos autores }\end{array}$ & $\begin{array}{l}\text { Concepção: L.C.S.; J.S.J. } \\
\text { Coleta de dados: L.C.S. } \\
\text { Análise de dados: L.C.S.; J.S.J. } \\
\text { Elaboração do manuscrito: L.C.S., J.S.J. } \\
\text { Revisões críticas de conteúdo intelectual importante: } \\
\text { L.C.S.; J.S.J. } \\
\text { Aprovação final do manuscrito: L.C.S.; J.S.J. }\end{array}$ \\
\hline $\begin{array}{l}\text { Consentimento } \\
\text { de uso de imagem }\end{array}$ & Não se aplica \\
\hline $\begin{array}{l}\text { Aprovação, ética } \\
\text { e consentimento }\end{array}$ & $\begin{array}{l}\text { O estudo foi aprovado pelo Comitê de Ética e Pesquisa CEP } \\
\text { - Universidade Estadual Paulista "Júlio de Mesquita Filho" - } \\
\text { UNESP/Assis. Faculdade de Ciências e Letras - FCL } \\
\text { CAAE: } 73652217.0 .0000 .5401 \\
\text { Número do Parecer: } 2.546 .924\end{array}$ \\
\hline Financiamento & Não houve financiamento \\
\hline
\end{tabular}

